\title{
Biogas Upgrading by Transition Metal Carbides
}

Christian Kunkel, Francesc Viñes," and Francesc Illas

Departament de Ciència de Materials i Química Fisica \& Institut de Química Teòrica $i$ Computacional (IQTCUB), Universitat de Barcelona, Martí i Franqués 1, 08028 Barcelona, Spain

AUTHOR INFORMATION

Corresponding Author

*francesc.vines@ub.edu

Keywords: Transition metal carbides - density functional theory - Biogas upgrading • $\mathrm{CO}_{2} / \mathrm{CH}_{4}$ separation $\bullet$ Transition state theory

\begin{abstract}
The separation of carbon dioxide $\left(\mathrm{CO}_{2}\right)$ from methane $\left(\mathrm{CH}_{4}\right)$ is critical in biogas upgrading, requiring materials with high selectivity towards one of the two gas components. Hereby we
\end{abstract}


show, by means of density functional theory based calculations including dispersive forces description, the distinct interaction of $\mathrm{CO}_{2}$ and $\mathrm{CH}_{4}$ with most stable (001) surfaces of seven transition metal carbides $(\mathrm{TMC} ; \mathrm{TM}=\mathrm{Ti}, \mathrm{Zr}, \mathrm{Hf}, \mathrm{V}, \mathrm{Nb}, \mathrm{Ta}, \mathrm{Mo})$. Transition state theory derived ad/desorption rates suggest a very high $\mathrm{CO}_{2}$ uptake and selectivity over $\mathrm{CH}_{4}$ even at ambient temperature and low partial gas pressures.

Serious concerns about climate change are associated with rising atmospheric concentrations of greenhouse gases like carbon dioxide $\left(\mathrm{CO}_{2}\right)$ and methane $\left(\mathrm{CH}_{4}\right) .{ }^{1}$ A reduction of emissions is needed, encouraging the use of renewable energies that contribute in satisfying the worldwide 
growing energy demand. ${ }^{1}$ Among other available technologies, biogas production from anaerobic digestion is a viable approach, ${ }^{2}$ offering a route towards $\mathrm{CH}_{4}$, an interesting energy source and carrier, obtainable in 50-75 v/v \% purity, but admixed with $25-50 \mathrm{v} / \mathrm{v} \% \mathrm{CO}_{2}$, which lowers the energy content but in turn allows a direct use in combined heat and power plants (CHPs) after removal of other minor constituents. ${ }^{3}$ The use of $\mathrm{CH}_{4}$ as fuel is to date hampered, requiring a purity $>95 \mathrm{v} / \mathrm{v} \%{ }^{3}$ Separation of $\mathrm{CO}_{2}$ while retaining $\mathrm{CH}_{4}$ in the gas stream is thus a critical step for biogas upgrading, ${ }^{3}$ whose concomitant economic and ecologic interest extends to other upgradable sources of $\mathrm{CO}_{2} / \mathrm{CH}_{4}$ mixtures, ${ }^{4}$ e.g. landfill and coal mine ventilation airs, and natural gas.

Despite both $\mathrm{CO}_{2}$ and $\mathrm{CH}_{4}$ are quite stable and mostly inactive, the noticeable $\mathrm{CO}_{2}$ quadrupole moment allows for a strong interaction with some privileged materials, ${ }^{5,6}$ a factor lacking in the nonpolar $\mathrm{CH}_{4}$, which weakly interacts with most of them. ${ }^{7}$ Thanks to such polarity differences, $\mathrm{CO}_{2} / \mathrm{CH}_{4}$ efficient separation seems a priori possible. However, materials with a high $\mathrm{CO}_{2}$ selectivity over $\mathrm{CH}_{4}$ at standard temperature/pressure operation conditions are needed. There is exhaustive experimental research on promising materials, ${ }^{8}$ yet performance regretfully often remains low.

Materials screening is conveniently first sieved from simulations accurately estimating the interaction of a given material with $\mathrm{CO}_{2}$ and $\mathrm{CH}_{4}$. Among other methods, ${ }^{7,9}$ density functional theory (DFT) including dispersion (DFT-D) has proven especially useful to size $\mathrm{CH}_{4}$ interactions with $\mathrm{Ni}^{10}$ and $\mathrm{Co}^{11}$ surfaces, nanoporous carbons, ${ }^{9}$ zeolites, ${ }^{7}$ periodic mesoporous phenylene-silica (PMOs), ${ }^{8}$ and metal organic frameworks (MOFs). ${ }^{12}$ Similar examples are available for $\mathrm{CO}_{2},{ }^{13}$ and, in combination with statistical thermodynamics based approaches, 
realistic and therefore useful estimates of selectivity and uptake rates are accessible. $^{8,14}$

We recently applied this computational strategy to assess $\mathrm{CO}_{2}$ capture on most stable and exhibited (001) surfaces of transition metal carbides (TMCs), with 1:1 TM:C ratio and rocksalt crystal structure under standard and moderate pressures. ${ }^{15} \mathrm{TiC}, \mathrm{ZrC}, \mathrm{HfC}, \mathrm{NbC}, \mathrm{TaC}$, and $\delta$-MoC were TMCs found to strongly adsorb and even activate $\mathrm{CO}_{2}$-a noteworthy case of $\mathrm{CO}_{2}$ chemisorption. This exceptional behavior can allow for $\mathrm{CO}_{2}$ capture even at ambient temperatures and low gas partial pressure, with the specific storage power dependent on the TMC composition. ${ }^{13}$ The $\mathrm{CO}_{2}$ capture and activation on TMCs, as predicted by DFT, has been previously directly evidenced by infrared spectroscopy and indirectly by its hydrogenation. ${ }^{16,17}$ Such reactivity suggest promising usage of TMCs to catalyze a wide variety of reactions, ${ }^{13,18}$ often equaling or surpassing Pt group catalysts performance, ${ }^{19}$ with the added benefit of low cost, chemical robustness, and poisoning resistance. ${ }^{18}$

Theoretical simulations on $\mathrm{CH}_{4}$ interaction with TMC surfaces are rather sparse. Only Tominaga et al. predicted $\mathrm{CH}_{4}$ reforming to ethylene on orthorhombic $\beta-\mathrm{Mo}_{2} \mathrm{C}$ surfaces, ${ }^{20}$ and a recent DFT-D study showed strong $\mathrm{CH}_{4}$ physisorption on $\delta$-MoC (001), with a predicted possible methane capture at room temperature. ${ }^{21}$ Indeed, molybdenum carbides are known to be very reactive TMCs, and $\mathrm{CH}_{4}$ adsorption is assumed to be weaker on others. That in mind, TMCs could then be suited for $\mathrm{CO}_{2}$ removal from mixed $\mathrm{CH}_{4} / \mathrm{CO}_{2}$ gas streams. To evaluate this possibility, we carried out a thorough DFT-D study of $\mathrm{CH}_{4}$ attachment to most stable (001) surfaces of seven different TMCs, providing a realistic estimate of initial $\mathrm{CO}_{2} / \mathrm{CH}_{4}$ selectivity. As done in previous works, ${ }^{13}$ we restrain our study to experimentally known rocksalt TMCs with 1:1 TM:C ratio, known to be the stable phase under standard and moderate pressure and 
temperature conditions. ${ }^{15}$ Thus structural aspects are circumvented and a meaningful comparison is feasible, while including group 4 ( $\mathrm{TiC}, \mathrm{ZrC}$, and $\mathrm{HfC}$ ), group 5 ( $\mathrm{VC}, \mathrm{NbC}$, and $\mathrm{TaC}$ ), and group $6(\delta-\mathrm{MoC})$ TMCs. Note that for MoC rocksalt packing is only present in the high temperature $\delta$-phase.

To assess the $\mathrm{CH}_{4}$ adsorption on the different TMCs, periodic DFT based calculations were carried out on suitable surface models using the Vienna Ab Initio Simulation Package VASP code. ${ }^{22}$ The Perdew-Burke-Ernzerhof $(\mathrm{PBE})^{23}$ exchange-correlation $(\mathrm{xc})$ functional was used to account for xc effects, to which the dispersion (van der Waals) correction D3 as proposed by Grimme (PBE-D3) ${ }^{24}$ was added. Further computational details are found in the Supporting Information. For the sake of the oncoming discussion clarity it is necessary to state that favourable adsorption energies, $E_{\text {ads }}$, are defined negative.

First, the surface exposed sites that most strongly interact with $\mathrm{CH}_{4}$ have been identified by a computational screening at PBE-D3 level: Four non-equivalent sites were tested for each TMC (001) model, namely bridge Mo-C (b), hollow (h), top $\mathrm{C}\left(\mathrm{t}^{\mathrm{C}}\right)$ and top metal $\left(\mathrm{t}^{\mathrm{M}}\right)$. Interaction at each site was evaluated with two different $\mathrm{CH}_{4}$ orientations, with either two or three $\mathrm{H}$ pointing towards the surface, denoted $\mathrm{H}_{2}$ and $\mathrm{H}_{3}$, respectively. ${ }^{21}$ Notice that orientations with a sole $\mathrm{H}$ pointing towards the TMC surface were neglected as previously found to be overall less favourable. ${ }^{21}$ Results show that all optimized structures yield rather similar $E_{\text {ads }}$ within a range of $0.1 \mathrm{eV}$. Still, $\mathrm{H}_{2}\left(\mathrm{t}^{\mathrm{M}}\right), \mathrm{H}_{3}(\mathrm{~b})$, and $\mathrm{H}_{3}\left(\mathrm{t}^{\mathrm{M}}\right)$ lead to most favourable adsorptions for all considered TMCs, to which further assessment is focused onto. The corresponding PBE-D3 adsorption energies are reported in Table 1. Results show that adsorption on $\mathrm{TiC}, \mathrm{ZrC}, \mathrm{HfC}$ (group 4) and $\mathrm{VC}, \mathrm{NbC}, \mathrm{TaC}$ (group 5) is favourable at PBE-D3 level, with $E_{a d s}$ values ranging -0.19 to - 
$0.23 \mathrm{eV}$, and well agreeing to DFT-D results on other materials, e.g. $-0.19 \mathrm{eV}$ on $\mathrm{Ni}$ (110) and (100) surfaces, ${ }^{10}$ or $-0.12 \mathrm{eV}$ on $\mathrm{MgO}(001) .^{25}$

Table 1. PBE-D3 adsorption energies, $E_{a d s}$, of $\mathrm{CH}_{4}$ on TMC (001) surfaces. Previously reported values for adsorbed $\mathrm{CO}_{2}$ are also included. ${ }^{13}$ All values are given in $\mathrm{eV}$.

\begin{tabular}{lccccc}
\hline $\boldsymbol{E}_{\text {ads }}$ & \multicolumn{3}{c}{$\mathbf{C H}_{\mathbf{4}}$} & \multicolumn{2}{c}{$\mathbf{C O}_{2}$} \\
& $\mathrm{H}_{2}\left(\mathrm{t}^{\mathrm{M}}\right)$ & $\mathrm{H}_{3}(\mathrm{~b})$ & $\mathrm{H}_{3}\left(\mathrm{t}^{\mathrm{M}}\right)$ & $\mathrm{MMC}$ & $\mathrm{TopC}$ \\
\hline $\mathrm{TiC}$ & -0.23 & -0.23 & -0.23 & -0.81 & -0.83 \\
$\mathrm{ZrC}$ & -0.23 & -0.23 & -0.23 & -1.56 & -1.60 \\
$\mathrm{HfC}$ & -0.23 & -0.23 & -0.23 & -1.62 & -1.65 \\
$\mathrm{VC}$ & -0.21 & -0.22 & -0.21 & $-0.19^{\mathrm{b}}$ & $-0.04^{\mathrm{b}}$ \\
$\mathrm{NbC}$ & -0.19 & -0.19 & -0.19 & -0.87 & -0.70 \\
$\mathrm{TaC}$ & -0.23 & -0.23 & $-0.21^{\mathrm{a}, \mathrm{c}}$ & -1.21 & -0.94 \\
$\delta$-MoC & -0.77 & $-0.77^{\mathrm{a}}$ & -0.76 & -1.20 & -1.03 \\
\hline
\end{tabular}

${ }^{\mathrm{a}}$ Spurious imaginary frequencies found, see main text and Supporting Information.

${ }^{\mathrm{b}}$ More stable physisorbed $E_{\text {ads }}$ of $-0.28 \mathrm{eV}$ was used for rate evaluation.

${ }^{\mathrm{c}}$ Minor convergence problems occurred, see discussion in Supporting Information.

Methane adsorption is almost exclusively due to dispersive forces, as revealed by comparing to PBE values, see Table S1 in the Supporting Information, where adsorption energies range +0.03 to $-0.02 \mathrm{eV}$, suggesting that the electronic interaction in between $\mathrm{CH}_{4}$ and TMC surfaces is almost negligible. Given the weak interaction neither significant distortion of $\mathrm{CH}_{4}$ nor of surface atoms is found. $\mathrm{CH}_{4}$ is adsorbed ranging 3.06 to $3.39 \AA$ away from the surface, distance measured by the vertical distance between methane carbon and highest surface carbon, see Fig. 1 and distances in Table S1 of the Supporting Information. Altogether, $\mathrm{CH}_{4}$ interaction on TMCs (001) surfaces can be safely related to physisorption. The $\delta$-MoC case is to 
be discussed apart; $\mathrm{E}_{\text {ads }}$ values are of the order of $\sim-0.8 \mathrm{eV}$, and so significantly higher compared to the rest of studied TMCs, and actually also electronically favored since PBE $E_{\text {ads }}$ values contribute $\sim-0.55 \mathrm{eV} .^{21}$

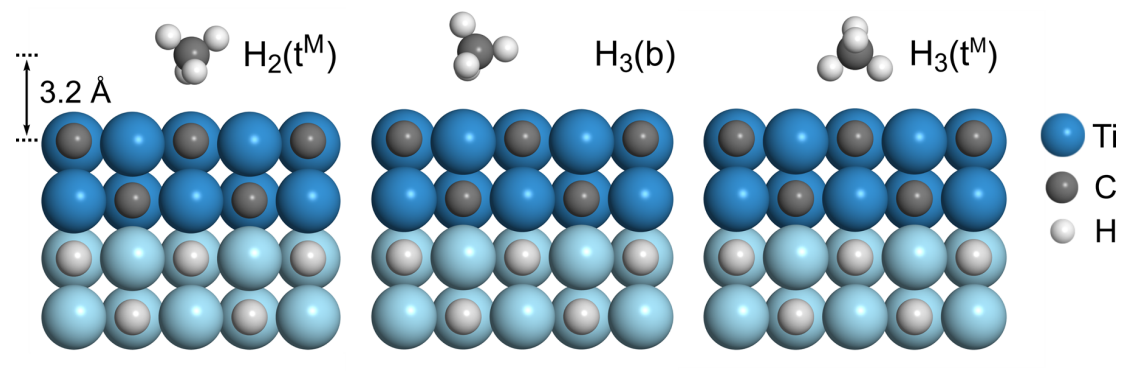

Figure 1. Side sketches of $\mathrm{CH}_{4}$ adsorbed on TiC (001) in the three different considered cases. Lighter color layers were fixed during optimization. For top views of all geometries, see Supporting Information.

With results for methane interaction laid out, a straight comparison to earlier results for $\mathrm{CO}_{2}$ adsorption ${ }^{22}$ allows a first assessment of selectivity. $\mathrm{CO}_{2}$ was found to adsorb strongly on two sites, namely MMC and TopC, see their PBE-D3 adsorption energies in Table 1. Direct comparison already suggests a high $\mathrm{CO}_{2}$ selectivity over $\mathrm{CH}_{4}$ for few $\mathrm{TMCs}(\mathrm{TM}=\mathrm{Ti}, \mathrm{Zr}, \mathrm{Hf}$, $\mathrm{Nb}, \mathrm{Ta}$ ): Adsorption energies for $\mathrm{CH}_{4}$ are on the order of $\sim-0.2 \mathrm{eV}$, while values for $\mathrm{CO}_{2}$ exceed these by 3.5 to 8 times, ranging from $\sim-0.7$ to $\sim-1.6 \mathrm{eV}$ depending on the TMC. On $\delta$-MoC both $\mathrm{CH}_{4}$ and $\mathrm{CO}_{2}$ adsorptions are rather strong; selectivity is therefore expected low yet molecular anchoring suited, which may be advantageous for catalytic applications such as methane dry reforming, where similar binding of both gases is needed. On the other hand, binding to VC is rather weak and the material likely unselective: $\mathrm{CO}_{2}$ physisorption has an $E_{a d s}$ of $-0.28 \mathrm{eV}$, comparable to methane interaction of $-0.22 \mathrm{eV}$. 
Further better-grounded evaluation of $\mathrm{CO}_{2}$ selectivity over $\mathrm{CH}_{4}$ is provided for the temperature range $50-1000 \mathrm{~K}$ as based on the estimation of adsorption and desorption rates from harmonic transition state theory (TST) using present DFT-D results, as fully explained in the Supporting Information. Notice that such theoretical approach has been successfully used to explain the experimental biogas upgrading in PMOs. ${ }^{8}$ In short, adsorption rates $r_{a d s}^{\mathrm{CO}_{2}}$ and $r_{a d s}^{\mathrm{CH}_{4}}$ for $\mathrm{CO}_{2}$ and $\mathrm{CH}_{4}$ depend on the impingement of molecules on the surfaces and therefore on their partial pressures. Here we evaluate these at two partial pressures, (i) 0.01 bar, for capture from dilute streams, e.g. coal mine ventilation air with $\mathrm{CO}_{2}$ and $\mathrm{CH}_{4}$ contents of $1 \mathrm{v} / \mathrm{v} \%$ each, ${ }^{7}$ and (ii) $1.0 \mathrm{bar}$, to assess gas enrichment at higher pressure, e.g. useful for pressure swing adsorption. We refrained the evaluation at higher partial pressures, as model validity could become compromised, see below.

Desorption rates differ for each of the identified sites given in Table 1, but a macroscopic rate is likely superimposed from all contributions, justifying the use of average desorption rates $r_{d e s}^{\mathrm{CO}_{2}}$ and $r_{d e s}^{\mathrm{CH}_{4}}$. For their calculation, two different models for entropy losses upon adsorption were devised, accounting for upper and lower limits, ${ }^{26}$ which help to rationalize such an effect. In the hindered model all translations and rotations are impeded upon adsorption and effectively converted to frustrated vibrations; in the free model gas-phase rotational and translational degrees are preserved, the latter in two dimensions above the surface, with the adsorbate fixed only in height. We initially evaluated both models for physisorbed species, namely for $\mathrm{CH}_{4}$ on all TMCs and $\mathrm{CO}_{2}$ on $\mathrm{VC}$, though for strongly chemisorbed $\mathrm{CO}_{2}$ on the other TMCs only the hindered model is considered, being the most likely situation. 
To clarify these models, their estimated ad/desorption rates are given in Fig. 2a for TiC (001). Only $\mathrm{CO}_{2}$ adsorption rates are depicted, as $\mathrm{CH}_{4}$ ones are simply higher by a factor of 1.7 , extracted from the $\mathrm{CH}_{4}$ smaller molar mass, see Supporting Information. The difference can be considered insignificant within the range of accuracy, though. Larger differing desorption rates are the main factor on selectivity. At intersection points of adsorption and desorption rates one can mark fringe temperatures, above which materials would likely lose their ability to capture significant amounts of $\mathrm{CH}_{4}$ or $\mathrm{CO}_{2}$. Taking $\mathrm{TiC}$ as an example, see Fig. 2a, one observes that at temperatures below $T_{1}=145 \mathrm{~K}$ and $\mathrm{T}_{2}=195 \mathrm{~K} \mathrm{CH}_{4}$ adsorption rate at 0.01 bar pressure regime is larger than desorption rates, for hindered and free models, respectively. These temperatures rise to $T_{3}=195 \mathrm{~K}$ and $T_{4}=270 \mathrm{~K}$ for the 1.0 bar pressure regime; in all cases, well below ambient temperature; so, $\mathrm{CH}_{4}$ would not be captured at ambient conditions. Equivalent fringe temperatures are found for $\mathrm{ZrC}, \mathrm{HfC}, \mathrm{NbC}, \mathrm{TaC}$, and $\mathrm{VC}$, as $\mathrm{CH}_{4}$ desorption rates do not significantly differ, and similar conclusions are extracted. 

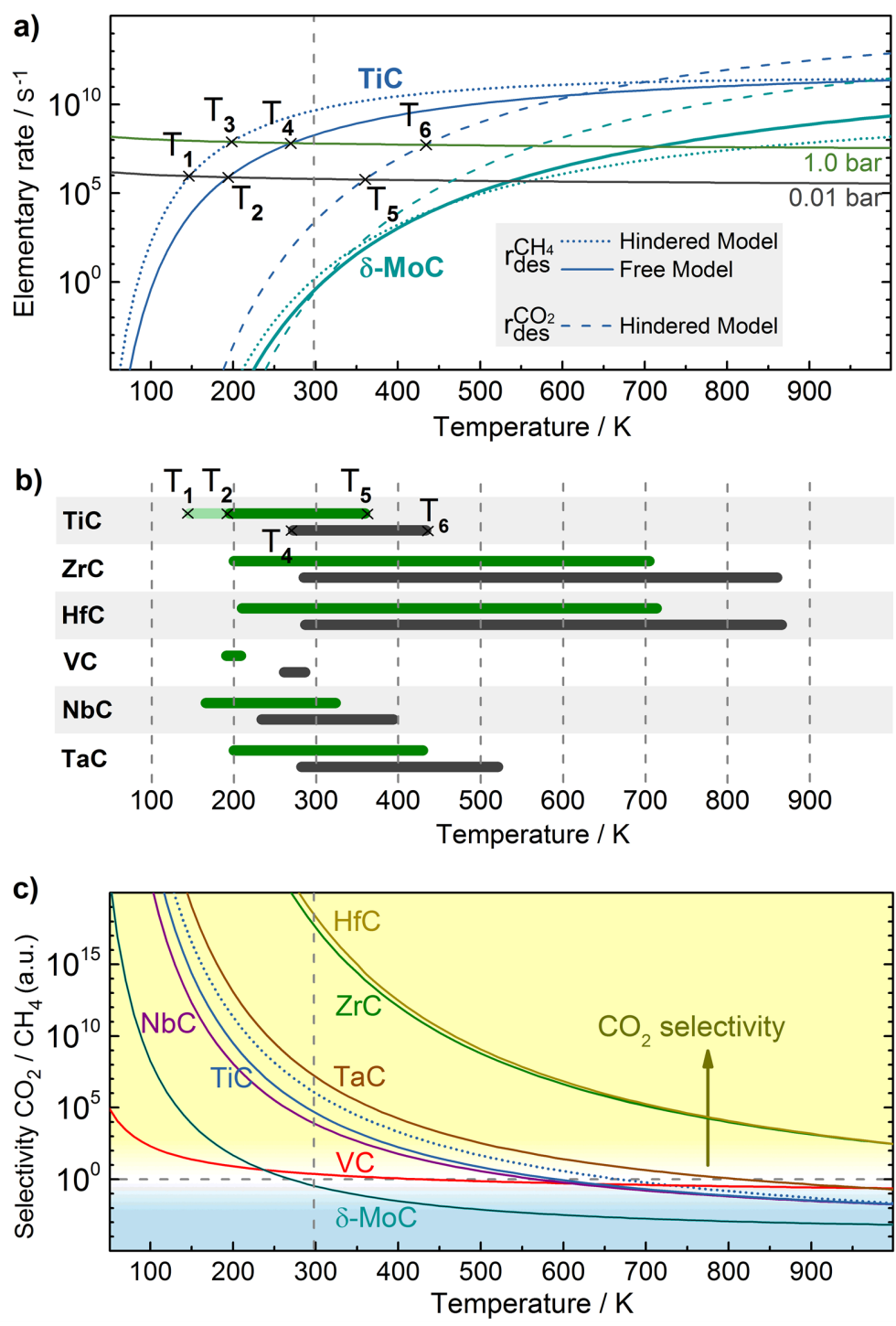

Figure 2. a) Temperature dependence of estimated desorption rates of $\mathrm{CO}_{2}$ and $\mathrm{CH}_{4}$ on $\mathrm{TiC}$ and d-MoC (001) surfaces, and adsorption rates for $\mathrm{CO}_{2}$ at different partial pressures. b) Temperature ranges for different TMC (001) surfaces, where $\mathrm{CO}_{2}$ adsorption is predicted high with nearly no $\mathrm{CH}_{4}$ capture. Solid green (dark gray) correspond to partial pressures of 0.01 bar (1.0 bar) evaluated according to free model. Light green gives the hindered model predictions for TiC. c) Temperature dependence of $\mathrm{CO}_{2}$ selectivity over $\mathrm{CH}_{4}$ for different TMCs. Solid (dashed) curves correspond to the free (hindered) model. Gray dashed horizontal and vertical lines highlight a selectivity value of 1 and ambient temperature of $\mathrm{T}=298 \mathrm{~K}$. 
For completeness, $\mathrm{T}_{5}=360 \mathrm{~K}$ and $\mathrm{T}_{6}=435 \mathrm{~K}$ mark temperatures below which $\mathrm{CO}_{2}$ accumulates on $\mathrm{TiC}$ at 0.01 and 1.0 bar, respectively, considerably high values that lead us to suggest these materials for $\mathrm{CO}_{2}$ capture. ${ }^{13}$ In combination with fringe $\mathrm{CH}_{4}$ temperatures $\mathrm{T}_{2}$ and $\mathrm{T}_{4}$, lower and higher temperature ends are marked where capture of high amounts of $\mathrm{CO}_{2}$ with good selectivity over $\mathrm{CH}_{4}$ are thus predicted. These ranges are graphically depicted in Fig. $2 \mathrm{~b}$ for all studied TMCs, with the exception of $\delta$-MoC, see below. According to this $\mathrm{TiC}, \mathrm{NbC}$, and $\mathrm{TaC}$ could be useful around ambient temperatures, whereas $\mathrm{ZrC}$ and $\mathrm{HfC}$ could be used even at higher temperatures. VC seems hardly usable for such application -as expected from weaker interaction with $\mathrm{CO}_{2}-$ with ranges only given to demonstrate this point. Note that free model values were used in such an analysis, providing the more conservative estimate, yet hindered model would extend the temperature range on the lower end; the example for $\mathrm{TiC}$ is provided for 0.01 bar partial pressure. Concerning $\delta-\mathrm{MoC}, \mathrm{CH}_{4}$ capture temperature ranges $460-520 \mathrm{~K}$ at 0.01 bar and $570-730 \mathrm{~K}$ at 1.0 bar partial pressures, suggest the material for $\mathrm{CH}_{4}$ capture, in line to previous estimates of $\sim 330 \mathrm{~K}$ in vacuum. ${ }^{21}$

Further estimates of low coverage $\mathrm{CO}_{2}$ selectivity over $\mathrm{CH}_{4}, \mathrm{~S}_{\mathrm{CO}_{2} / \mathrm{CH}_{4}}$ are obtained for equal $\mathrm{CO}_{2}$ and $\mathrm{CH}_{4}$ partial pressures. Selectivity is defined through adsorption/desorption equilibrium constants $\mathrm{K}_{\mathrm{CO}_{2}}$ and $\mathrm{K}_{\mathrm{CH}_{4}}$

$$
\mathrm{S}_{\mathrm{CO}_{2} / \mathrm{CH}_{4}}=\frac{\mathrm{K}_{\mathrm{CO}_{2}}}{\mathrm{~K}_{\mathrm{CH}_{4}}}=\frac{\mathrm{r}_{\text {ads }}^{\mathrm{CO}_{2}} / \mathrm{r}_{\text {des }}}{\mathrm{CO}_{2}}
$$

Again, $\mathrm{S}_{\mathrm{CO}_{2} / \mathrm{CH}_{4}}$ can be evaluated from hindered or free models: A comparison is made for TiC, see Fig. 2c: Hindered model selectivities are $\sim 2$ orders of magnitude higher compared to free model values, yet qualitative conclusions remain similar. So, further discussion is restricted to 
more conservative free model. Among all studied TMCs, $\mathrm{CO}_{2}$ selectivity is rather high for TiC, $\mathrm{NbC}$, and $\mathrm{TaC}$ and very high for $\mathrm{ZrC}$ and $\mathrm{HfC}$, with a wider working temperature range. According to this, selectivity values of $10^{5}$ or higher are predicted even for very low partial pressures of 0.01 bar, which, in theory, ensure a biogas $\mathrm{CH}_{4}$ enrichment above $99.9 \%$. In contrast, a rather low selectivity is expected for $\mathrm{VC}$ and $\delta-\mathrm{MoC}$, but the latter does capture both $\mathrm{CH}_{4}$ and $\mathrm{CO}_{2}$, interesting for possible use in methane dry reforming at moderate temperatures.

Note that present estimations are given for initial adsorption stages, ${ }^{8}$ where adsorbate lateral interactions are disregarded. For $\mathrm{CO}_{2}$ at medium coverages, these are found not to be repulsive, seen e.g. on $\mathrm{Ni}^{27}$ or $\alpha-\mathrm{Mo}_{2} \mathrm{C}^{28}$ surfaces. $\mathrm{For}_{\mathrm{CH}_{4}}$ pair interactions become increasingly favourable with coverage, ${ }^{29}$ e.g. in MOF pores ${ }^{14}$ or on $\mathrm{MgO}(001)$ surface. ${ }^{29}$ This effect would decrease $\mathrm{CO}_{2}$ selectivity at higher pressures. However, $\mathrm{CO}_{2}$ selectivity is expected to prevail, due to its stronger adsorption.

While keeping these points in mind, a first assessment of the materials $\mathrm{CO}_{2}$ adsorption capacity seems necessary. Interestingly, this is possible when knowing the specific surface area of a TMC powder sample. We use here a reasonable and conservative estimate of $50 \mathrm{~m}^{2} / \mathrm{g}$, justified by values of 450,200,140, and $22 \mathrm{~m}^{2} / \mathrm{g}$ reported by Giordano et al. ${ }^{30}$ for nanoparticles of $\mathrm{VC}, \mathrm{TiC}, \mathrm{NbC}$, and $\mathrm{Mo}_{2} \mathrm{C}$. For an assumed half monolayer coverage of $\mathrm{CO}_{2}$ on each $\mathrm{TMC}$ surface slab - 2x2 surface slab areas range from 75.0 to $89.1 \AA^{2}$ with in total four $\mathrm{CO}_{2}$ molecules assumed to be adsorbed-, exemplary capacities of 1.6 to $1.9 \mathrm{wt} \%$ are found, comparable in magnitude to $2.2 \mathrm{wt} \%$ found at $323 \mathrm{~K}$ for $\mathrm{MgO}$ with a specific surface area of $32 \mathrm{~m}^{2} / \mathrm{g}$. ${ }^{31} \mathrm{In}$ combination with the herein demonstrated high $\mathrm{CO}_{2}$ selectivity over $\mathrm{CH}_{4}$, specifically synthesized TMC samples exhibiting higher specific surface areas ${ }^{32}$ could prove as highly 
performing materials. Similar strategies have been successfully applied to significantly increase $\mathrm{CO}_{2}$ capture capacity on porous $\mathrm{MgO}$ samples. ${ }^{31}$

In summary, periodic DFT PBE-D3 calculations on the interaction of $\mathrm{CH}_{4}$ with most stable (001) surfaces of seven transition metal carbides (TMCs) predict a weak $\mathrm{CH}_{4}$ attachment for groups 4 and 5 TMCs (TM=Ti, Zr, Hf, V, Nb, Ta) with adsorption energies of $\sim-0.2 \mathrm{eV}$, almost exclusively dominated by dispersion. In contrast $\delta$-MoC (group 6) displays a strong interaction with $\mathrm{CH}_{4}$ of $\sim-0.8 \mathrm{eV}$. Comparison to earlier results of strong $\mathrm{CO}_{2}$ interaction on these materials suggest a highly preferred $\mathrm{CO}_{2}$ adsorption over $\mathrm{CH}_{4}$ when $\mathrm{TMCs}(\mathrm{TM}=\mathrm{Ti}, \mathrm{Zr}$, $\mathrm{Hf}, \mathrm{Nb}, \mathrm{Ta}, \mathrm{Mo}$ ) are exposed to $\mathrm{CO}_{2} / \mathrm{CH}_{4}$ mixtures. Adsorption and desorption rate estimates mark temperature ranges around ambient conditions ( $\mathrm{TiC}$ and $\mathrm{NbC}$ ) or even up to elevated temperatures $(\mathrm{ZrC}, \mathrm{HfC}$, and $\mathrm{TaC})$ at which $\mathrm{CO}_{2}$ capture selectivities above $99.9 \%$ are expected even at very low partial pressures, highlighting the usage of such $\mathrm{TMCs}$ for $\mathrm{CO}_{2}$ separation from $\mathrm{CH}_{4}$ in biogas upgrading. 


\section{ASSOCIATED CONTENT}

The Supporting Information is available free of charge on the ACS Publications website.

Additional computational details, list of adsorption energies and contributions, and geometric descriptors, top views of ad-sorbate structures, brief explanation of the used rate model.

\section{AUTHOR INFORMATION}

\section{Corresponding Author}

*francesc.vines@ub.edu

\section{Notes}

The authors declare no competing financial interests.

\section{ACKNOWLEDGMENTS}

This work was supported by Spanish Ministerio de Economía y Competitividad (MEC) CTQ2015-64618-R grant and, in part, by Generalitat de Catalunya grants 2014SGR97 and XRQTC, and by the Novel Materials Discovery (NOMAD) Laboratory, A European Center of Excellence which has received funding from the European Union's Horizon 2020 research and innovation programme under grant agreement No 676580. F.V. thanks Spanish MEC for a Ramón y Cajal research contract (RYC-2012-10129). F.I. acknowledges additional support from the 2015 ICREA Academia Award for Excellence in University Research.

\section{REFERENCES}

(1) Scenario, N. P.; East, M. World energy outlook 2014; International Energy Agency (IEA) Publishing, Paris, France, 2014. 
(2) Weiland, P. Biogas Production: Current State and Perspectives. Appl. Microbiol. Biotechnol. 2010, 85, 849-860.

(3) Sun, Q.; Li, H.; Yan, J.; Liu, L.; Yu, Z.; Yu, X. Selection of Appropriate Biogas Upgrading Technology - A Review of Biogas Cleaning, Upgrading and Utilisation. Renew. Sustain. Energy Rev. 2015, 51, 521-532.

(4) Bae, Y. S.; Snurr, R. Q. Development and Evaluation of Porous Materials for Carbon Dioxide Separation and Capture. Angew. Chemie 2011, 50, 11586-11596.

(5) Freund, H.; Roberts, M. W. Surface Chemistry of Carbon Dioxide. Surf. Sci. Rep. 1996, $25,225-273$.

(6) Taifan, W.; Boily, J. Surface Chemistry of Carbon Dioxide Revisited. Surf. Sci. Rep. 2016, 71, 595-671.

(7) Kim, J.; Maiti, A.; Lin, L.-C.; Stolaroff, J. K.; Smit, B.; Aines, R. D. New Materials for Methane Capture from Dilute and Medium-Concentration Sources. Nat. Commun. 2013, 4, 1694.

(8) Kunkel, C.; Viñes, F.; Lourenço, M. A. O.; Ferreira, P.; Gomes, J. R. B.; Illas, F. Selectivity for $\mathrm{CO}_{2}$ over $\mathrm{CH}_{4}$ on a Functionalized Periodic Mesoporous Phenylene-Silica Explained by Transition State Theory. Chem. Phys. Lett. 2017, 671, 161-164.

(9) Ihm, Y.; Cooper, V. R.; Gallego, N. C.; Contescu, C. I.; Morris, J. R. MicrostructureDependent Gas Adsorption: Accurate Predictions of Methane Uptake in Nanoporous Carbons. $J$. Chem. Theory Comput. 2014, 10, 1-4.

(10) González, S.; Viñes, F.; García, J. F.; Erazo, Y.; Illas, F. A DF-vdW Study of the $\mathrm{CH}_{4}$ Adsorption on Different Ni Surfaces. Surf. Sci. 2014, 625, 64-68. 
(11) Hao, X.; Wang, Q.; Li, D.; Zhang, R.; Wang, B. The Adsorption and Dissociation of Methane on Cobalt Surfaces: Thermochemistry and Reaction Barriers. RSC Adv. 2014, 4, 4300443011.

(12) Yang, Q.; Liu, D.; Zhong, C.; Li, J. Development of Computational Methodologies for Metal-Organic Frameworks and Their Application in Gas Separations. Chem. Rev. 2013, 113, 8261-8323.

(13) Kunkel, C.; Viñes, F.; Illas, F. Transition Metal Carbides as Novel Materials for CO Capture, Storage, and Activation. Energy Environ. Sci. 2016, 9, 141-144.

(14) Sillar, K.; Sauer, J. Ab Initio Prediction of Adsorption Isotherms for Small Molecules in Metal-Organic Frameworks: The Effect of Lateral Interactions for Methane/CPO-27-Mg. J. Am. Chem. Soc. 2012, 134, 18354-18365.

(15) Srivastava, A.; Chauhan, M.; Singh, R.K. High-Pressure Phase Transitions in Transition Metal Carbides XC (X=Ti, Zr, Hf, V, Nb, Ta): A First-Princple Study. Phase Transitions 2011, $84,58-66$

(16) Porosoff, M. D.; Kattel, S.; Li, W.; Liu, P.; Chen, J. G. Identifying Trends and Descriptors for Selective $\mathrm{CO}_{2}$ Conversion to $\mathrm{CO}$ over Transition Metal Carbides. Chem. Commun. 2015, 51, 6988-6991.

(17) Liu, X.; Kunkel, C.; Ramírez de la Piscina, P.; Homs, N.; Viñes, F.; Illas, F. Effective and Highly Selective $\mathrm{CO}$ Generation from $\mathrm{CO}_{2}$ Using a Polycrystalline $\alpha-\mathrm{Mo}_{2} \mathrm{C}$ Catalyst. ACS Catal . 2017, 7, 4323-4335.

(18) Hwu, H. H.; Chen, J. G. Surface Chemistry of Transition Metal Carbides. Chem. Rev. 2005, $105,185-212$.

(19) Levy, R. B.; Boudart, M. Platinum-like Behavior of Tungsten Carbide in Surface Catalysis. Science 1973, 181, 547-549. 
(20) Tominaga, H.; Nagai, M. Theoretical Study of Methane Reforming on Molybdenum Carbide. Appl. Catal. A Gen. 2007, 328, 35-42.

(21) Posada-Pérez, S.; dos Santos Politi, J. R.; Viñes, F.; Illas, F. Methane Capture at Room Temperature: Adsorption on Cubic $\delta$-MoC and Orthorhombic $\beta-\mathrm{Mo}_{2} \mathrm{C}$ Molybdenum Carbide (001) Surfaces. RSC Adv. 2015, 5, 33737-33746.

(22) Kresse, G.; Furthmüller, J. Efficient Iterative Schemes for Ab Initio Total-Energy Calculations Using a Plane-Wave Basis Set. Phys. Rev. B 1996, 54, 11169- 11186.

(23) Perdew, J. P.; Burke, K.; Ernzerhof, M. Generalized Gradient Approximation Made Simple. Phys. Rev. Lett. 1996, 77, 3865-3868.

(24) Grimme, S.; Ehrlich, S.; Goerigk, L. Effect of the Damping Function in Dispersion Corrected Density Functional Theory. J. Comput. Chem. 2011, 32, 1456-1465.

(25) Boese, A. D.; Sauer, J. Accurate Adsorption Energies for Small Molecules on Oxide Surfaces: $\mathrm{CH}_{4} / \mathrm{MgO}(001)$ and $\mathrm{C}_{2} \mathrm{H}_{6} / \mathrm{MgO}(001)$. J. Comput. Chem. 2016, 37, 2374-2385.

(26) Tait, S. L.; Dohnálek, Z.; Campbell, C. T.; Kay, B. D. n-alkanes on MgO(100). I. Coverage-dependent Desorption Kinetics of n-butane. J. Chem. Phys. 2005, 122, 164708.

(27) Wang, S.-G.; Cao, D.-B.; Li, Y.-W.; Wang, J.; Jiao, H. Chemisorption of $\mathrm{CO}_{2}$ on Nickel Surfaces. J. Phys. Chem. B 2005, 109, 18956-18963.

(28) Luo, Q.; Wang, T.; Walther, G.; Beller, M.; Jiao, H. Molybdenum Carbide Catalysed Hydrogen Production from Formic Acid - A Density Functional Theory Study. J. Power Sources 2014, 246, 548-555.

(29) Tosoni, S.; Sauer, J. Accurate Quantum Chemical Energies for the Interaction of Hydrocarbons with Oxide Surfaces: $\mathrm{CH}_{4} / \mathrm{MgO}(001)$. Phys. Chem. Chem. Phys. 2010, 12, 1433014340. 
(30) Giordano, C.; Erpen, C.; Yao, W.; Milke, B.; Antonietti, M. Metal Nitride and Metal Carbide Nanoparticles by a Soft Urea Pathway. Chem. Mater. 2009, 21, 5136-5144.

(31) Ding, Y.; Song, G.; Zhu, X.; Chen, R.; Liao, Q. Synthesizing MgO with a High Specific Surface for Carbon Dioxide Adsorption. RSC Adv. 2015, 5, 30929-30935.

(32) Flaherty, D. W.; May, R. A.; Berglund, S. P.; Stevenson, K. J.; Mullins, C. B. Low Temperature Synthesis and Characterization of Nanocrystalline Titanium Carbide with Tunable Porous Architectures. Chem. Mater. 2010, 22, 319-329. 


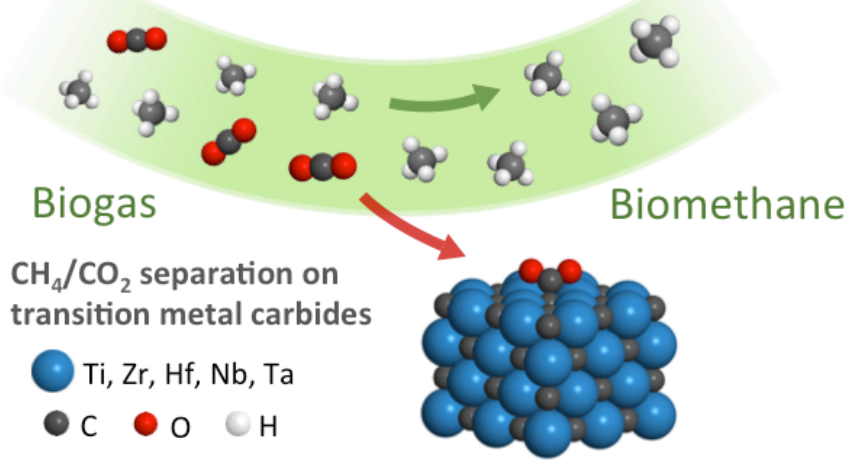

